NBER WORKING PAPER SERIES

\title{
QUALITY-CONSTANT PRICE INDEXES FOR THE ONGOING TREATMENT OF SCHIZOPHRENIA: AN EXPLORATORY STUDY
}

\author{
Richard G. Frank \\ Ernst R. Berndt \\ Alisa B. Busch \\ Anthony F. Lehman \\ Working Paper 10022 \\ http://www.nber.org/papers/w10022 \\ NATIONAL BUREAU OF ECONOMIC RESEARCH \\ 1050 Massachusetts Avenue \\ Cambridge, MA 02138 \\ October 2003
}

National Institute of Mental Health funding from grants R01MH62028 and R01MH59254 is gratefully acknowledged, as is additional funding to Dr. Busch by the Dr. Ralph and Marian Falk Medical Research Trust. An earlier version of this paper was presented at the International Health Economics Association meetings in San Francisco, CA, June, 2003, and at the Summer Institute meetings of the National Bureau of Economic Research in Cambridge, MA, July 2003. The views expressed herein are those of the authors and are not necessarily those of the National Bureau of Economic Research.

C2003 by Richard G. Frank, Ernst R. Berndt, Alisa B. Busch, and Anthony F. Lehman. All rights reserved. Short sections of text, not to exceed two paragraphs, may be quoted without explicit permission provided that full credit, including $(\mathrm{C}$ notice, is given to the source. 
Quality-Constant Price Indexes for the Ongoing Treatment of Schizophrenia: An Exploratory Study

Richard G. Frank, Ernst R. Berndt, Alisa B. Busch, and Anthony F. Lehman

NBER Working Paper No. 10022

October 2003

JEL No. I1, C8, O3

\begin{abstract}
$\underline{\text { ABSTRACT }}$
Health care expenditures have been increasing sharply in the last ten years, with spending on mental health disorders being particularly prominent. Over the same time period, a number of new antipsychotic medications have been added to the armamentarium for treatment of persons diagnosed with schizophrenia. Due in part to the sharply increased expenditures by Medicaid on mental health disorders such as schizophrenia, controversies have arisen as to the use of these more costly innovative medications, particularly their impact on the annualized cost of treating patients.

Using Medicaid data on 12,864 person years from two counties in Florida over the 1994-95 to 19992000 time period, in this study we address three issues: (i) On a per person year basis, what is happening over time to the mental health-related costs of treating schizophrenia? (ii) How is the composition and quality of care changing over time? and (iii) Holding quality of care constant, on a per person year basis, by how much are the costs for the ongoing treatment of schizophrenia changing?

We find that unadjusted for changes in quality of care over time, the annualized costs for the ongoing treatment of schizophrenia per person have increased about $0.5 \%$ per year. The composition of treatments for schizophrenia has changed substantially over this six-year time period, toward more intensive use of atypical antipsychotics, and away from psychotherapy. Holding treatment quality type and patient characteristics constant over time, mean treatment costs have fallen about $5.5 \%$ per year between 1994-1995 and 1999-2000.
\end{abstract}

Richard G. Frank

Department of Health Care Policy

Harvard Medical School

180 Longwood Avenue

Boston, MA 02115

and NBER

frank@hcp.med.harvard.edu

Ernst R. Berndt

MIT

Alfred P. Sloan School of Management

50 Memorial Drive, E52-452

Cambridge, MA 02142

and NBER

eberndt@mit.edu
Alisa Busch

McLean Hospital

Proctor Building

115 Mill Street

Belmont, MA 02478

abusch@hcp.med.harvard.edu

Anthony F. Lehman

Department of Psychiatry

University of Maryland School of Medicine

701 W. Pratt Street

Suite 388

Baltimore, MD 21201

alehman@psych.umaryland.edu 


\section{QUALITY-CONSTANT PRICE INDEXES FOR THE ONGOING TREATMENT OF SCHIZOPHRENIA:} AN EXPLORATORY STUDY

by Richard G. Frank, Ph.D., Ernst R. Berndt, Ph.D., Alisa B. Busch, M.D. and Anthony F. Lehman, M.D.

\section{INTRODUCTION}

Healthcare expenditures have been increasing sharply in the last ten years, with spending on mental health disorders being particularly prominent. ${ }^{1}$ A disproportionate share of mental health spending is for people with severe and persistent mental illnesses such as schizophrenia. ${ }^{2}$ During the 1990 s significant innovations have occurred in the treatment technologies available to clinicians caring for people with schizophrenia. In addition, based on a generation's worth of clinical studies, a great deal of effort has been expended in disseminating recommendations for "best practice" in treatment of schizophrenia. ${ }^{3}$ Together these changes in technology, coupled with quality improvement efforts, might be expected to substantially alter patterns of treatment for schizophrenia, resulting in both cost and quality of care changes.

Here we assess how the level of spending required to achieve particular levels of quality of care in the treatment of schizophrenia has changed during the 1990s. Our empirical analysis focuses on constructing price indexes for the ongoing treatment of schizophrenia. Through the creation of a price index that takes account of the quality of care, we provide a key building block in assessing aggregate productivity of spending in the mental health sector. To the best of our knowledge, to date there has been no study on price indexes for the ongoing treatment of schizophrenia. ${ }^{4}$

Schizophrenia is a chronic and disabling illness. Although no cure has been found for schizophrenia, its symptoms and manifestations are amenable to treatment. In the last decade, a number of new antipsychotic medications have been added to the treatment armamentarium; these innovative pharmaceuticals are generally known as atypical antipsychotics. Because of the disabling consequences of schizophrenia, the vast majority of treatment for schizophrenia in the U.S. is financed from public sector sources, such as Medicaid. It is estimated that in the U.S., approximately $70 \%$ of all prescriptions for antipsychotic medications are paid for by Medicaid. ${ }^{5}$ Due in part to the sharply increased expenditures by Medicaid on mental health disorders such as 
schizophrenia, controversies have arisen as to the use of these more costly innovative medications, particularly their impact on the annualized cost of treating patients. ${ }^{6}$

Using Medicaid data on 12,864 person years from two counties in Florida over the 1994-95 to 19992000 time period, in this study we address three specific issues: (i) On a per person year basis, what is happening over time to the mental health-related costs of treating schizophrenia? (ii) How is the composition and quality of care changing over time? And (iii), holding quality of care constant, on a per person year basis, by how much are the costs for the ongoing treatment of schizophrenia changing over time? We pursue these issues by constructing producer price indexes for treatment of schizophrenia. We base these price indexes and our quality adjustments on annual episodes of care. This allows us to make use of results from clinical research to control for quality which would not be possible using more traditional price indexes based directly on input prices (Berndt et al. [2000]).

\section{SCHIZOPHRENIA: THE ILLNESS, ITS PREVALENCE AND TREATMENTS}

Schizophrenia is a profound mental disorder characterized by loss of contact with reality (psychosis), hallucinations, delusions (false beliefs), abnormal thinking, and disrupted work and social functioning. ${ }^{7}$ The prevalence of schizophrenia worldwide appears to be about one percent, although pockets of higher or lower prevalence have been identified. In the U.S. about 2.5 million Americans are affected by schizophrenia, while an estimated 1.7 million are under treatment. The disease strikes at an early age, and generally materially alters the affected individual's life trajectory in social, educational and vocational domains. The peak age of onset is $15-25$ years in men and 25-35 years in women. ${ }^{8}$ The initial few years of the illness are the most turbulent, characterized by diminution of usual life roles (student, spouse, employee, parent) and acute episodes of crisis treatment (hospitalizations and emergency room visits).

Schizophrenia is a chronic and disabling illness. In the U.S. it accounts for about $2.5 \%$ of all health care costs, $20 \%$ of all Social Security disability days, and about $20-30 \%$ of the homeless. ${ }^{9}$ In the first ten years of the illness it is associated with about a $10 \%$ risk of suicide. On average, schizophrenia reduces the life span of those directly affected by about ten years. No matter the status of family of origin, schizophrenia frequently 
leads to high under- and unemployment, resulting in poverty, and very often, reliance upon publicly funded health care.

Schizophrenia is characterized by a constellation of symptoms, including positive symptoms (delusions, hallucinations), depressive symptoms (sadness, suicidality), negative symptoms (abnormal restricted emotional expression, abnormal restricted social interaction), and cognitive symptoms (impairments in memory, and in cognitive function). ${ }^{10}$

No definitive test exists to diagnose schizophrenia, but there is ample evidence pointing toward both genetic and acquired factors in etiology. Typically a psychiatrist makes the diagnosis based on a comprehensive assessment of the person's history and symptoms. To establish the diagnosis of schizophrenia, symptoms must persist for at least six months and be associated with significant deterioration of work, school, or social functioning. Often information from family, friends, or teachers is important in establishing when the illness began.

At this time there is no known cure for schizophrenia. The general goals of medical treatment are to decrease the frequency, severity and psychosocial consequences of episodes, and to maximize time without symptoms. Antipsychotic drugs, psychological interventions, family interventions, vocational rehabilitation and assertive community support activities represent the major components of available evidence-based treatments.

From 1955 up through the early 1990s, conventional or typical antipsychotics (e.g., haloperidol, chlorpromazine, fluphenazine, molindone and thioridazine, each of which blocks dopamine receptors in the brain) were the mainstay of pharmacological treatment. It is estimated that use of these conventional antipsychotics resulted in $40-50 \%$ reductions in annual relapse rates in the usual practice environment, and about $70 \%$ in randomized controlled trials. ${ }^{11}$ These pharmacotherapies are more effective in treating the positive than the negative symptoms, but frequently result in side effects of sedation, muscle stiffness, tremors and weight gain, as well as extrapyramidal side effects (EPS) such as tardive dyskinesia (an involuntary movement disorder most often characterized by puckering of the lips and tongue, or writhing of the arms or 
legs, which may not disappear even after the drug is discontinued, and for which currently there is no effective treatment).

In 1991, clozapine was introduced into the U.S. as the first in a new therapeutic class of drugs called atypical antipsychotics. This first generation of atypical antipsychotics blocks both dopamine and serotonin receptors in the brain, is more effective than the typicals in the $30-50 \%$ of treatment refractory patients, and results in fewer EPS. However, for 1-2\% of individuals taking clozapine, a potentially life-threatening condition called agranulocytosis (drop in the white blood cell count) occurs. Patients taking clozapine must have their white blood cell counts measured on a regular basis (e.g., every two weeks after being titrated), and satisfactory laboratory test results must be communicated to the pharmacist before a prescription can be dispensed. For this reason, clozapine is generally used only for individuals who did not respond to conventional antipsychotic drugs.

Beginning in 1993, a number of so-called second-generation atypical antipsychotics (e.g., risperidone, olanzapine, quetiapine, ziprasidone, and aripiprazole) received FDA approval for the treatment of schizophrenia. These second generation atypicals are not associated with agranulocytosis or EPS; they have similar efficacy for positive symptoms and superior efficacy than the typicals for negative symptoms. However, currently there is concern and controversy over side effects of the second generation atypicals, such as sedation, weight gain, arrhythmias associated with prolongation of the $\mathrm{QT}_{\mathrm{c}}$ interval, and impacts on glucose and cholesterol levels. ${ }^{12}$

At the present time, generic versions of the conventional antipsychotics and clozaril are on the market in the US, while the second-generation atypicals all still have patent protection and market exclusivity. The second generation atypicals are therefore considerably more expensive per day of therapy than the generic version of the other antipsychotics. In spite of their higher cost, however, the second generation atypicals now dominate the pharmacological treatment of schizophrenia. According to Berndt [2002], based on IMS Health data, in 2001 second generation atypicals accounted for $92 \%$ of all expenditures on antipsychotics, first generation atypicals garnered only $4-5 \%$, while the conventional antipsychotics comprised less than $2 \%$ of all antipsychotic expenditures. 


\section{THE PATIENT OUTCOMES RESEARCH TEAM (PORT) TREATMENT RECOMMENDATIONS}

In 1992 the Agency for Health Care Policy and Research and the National Institute of Mental Health launched the schizophrenia Patient Outcomes Research Team (PORT) project (Lehman et al. [1998a]). PORT treatment recommendations were published in January 1998. PORT placed a strong emphasis on the evidentiary basis for its treatment recommendations, particularly in the context of fiscal constraints: "Evidence based medicine reflects a commitment to providing medical treatments supported by scientific data on efficacy as well as the ongoing assessment of outcomes so that treatment can continually improve. Fiscal pragmatism commits us to the rational use of medical resources to ensure quality and efficiency." 13

The PORT study made more than twenty recommendations ranging from pharmacotherapy (presence and ranges according to acuity of treatment phase) to psychosocial treatments. Five of the PORT quality indicators can be observed in Medicaid retrospective claims data, and thus we focus on these five treatment types : pharmacotherapies, psychological treatments, family interventions, vocational rehabilitation, and case management and assertive community treatment.

With respect to pharmacotherapies, there is considerable evidence showing reductions in annual relapse rates (from $70 \%$ to $25 \%$ in efficacy trials, and to $40-50 \%$ in usual practice studies) associated with use of the various antipsychotic agents. Whether the current market domination by the second generation atypicals is warranted based on fiscal pragmatism grounds remains a controversial issue, and, according to Lehman, "...must be addressed by non-industry-sponsored cost-effectiveness studies." ${ }^{14}$

In terms of psychological interventions, the PORT study noted that "supportive, 'reality-based' individual and group therapy that focuses on practical life problems associated with the illness are helpful", although there is still considerable need for research on supportive psychotherapy, and on cognitive behavioral therapy. PORT recommended that each of these psychological interventions should be offered in conjunction with pharmacotherapy. ${ }^{15}$

PORT also cited evidence in support of the value of family interventions in reducing symptom relapses, when used in combination with medications, that resulted in 50\% less relapses than for patients 
receiving medication alone, and persisted for at least two years. PORT recommended that family psychoeducational interventions should be offered to all patients with schizophrenia who have ongoing contact with their families. ${ }^{16}$

In terms of evidence regarding the value of vocational rehabilitation programs, while such efforts increased vocational activities during the time patients participated in them, to date studies "...have not shown consistent or significant impacts on outcomes". ${ }^{17}$

A final area of intervention on which PORT summarized the existing evidentiary platform is assertive community treatment, in which multidisciplinary teams treat patients who are at high risk for hospital readmission and who cannot be maintained by other community-based treatment. Although the data are not completely consistent, they "...point to the value of treatment programs that combine medications with a range of psychosocial services. Provision of such packages of services likely reduces the need for crisis-oriented care and enables greater recovery". 18

In summarizing findings from the PORT study, director Anthony Lehman delineated the public health policy dilemma regarding treatment for people with schizophrenia as follows:

"We can now target resources to improve outcomes for schizophrenia. While it is hoped that this will also contain costs, high-quality care could cost more. Indeed, if one considers the minimalist nature of today's care of most persons with schizophrenia, it would not be surprising to find that it does. Perhaps reductions in crisis-oriented care will offset these costs, but others have pointed out that improved medical technologies, short of a cure, typically increase treatment costs." ${ }^{19}$

The PORT study recommendations, and the delineation of this public health policy dilemma, therefore lead us to focus in this paper on the following research issues: (i) on a per patient year basis, what is happening over time to the costs of treating schizophrenia? (ii) how is the quality of care for treatment of schizophrenia changing over time? and (iii) holding quality of care constant, on a per patient year basis, by how much are the costs of treating schizophrenia changing?

\section{THE FLORIDA MEDICAID DATA}

Our data encompass Medicaid retrospective administrative medical claims data for individuals diagnosed with and treated for schizophrenia in two counties in Florida, those containing Jacksonville and 
Orlando, for the six fiscal years between 1994-1995 and 1999-2000. The medical claims data include inpatient and outpatient procedure codes (both CPT and Florida Medicaid-specific), pharmacy data, mental healthrelated diagnoses, and the timing of any services. Enrollees in these Medicaid programs receive services in the context of a lightly managed fee-for-service environment, in which the primary care physicians receive a capitation payment for providing case management and gatekeeping services (known as primary care case management or PCCM). Mental health services are not carved out in these two counties. ${ }^{20}$

We constructed continuous enrollment cohorts of Medicaid enrollees. To be eligible, the individual must be age 18-64, have no break in Medicaid enrollment greater than two months, and the sum of nonMedicaid enrolled months plus months in a state Medicaid HMO program (also present in these two counties, but for which utilization data are unavailable) must be less than six. We used the Medicaid enrollment files to determine the race, sex, Medicaid eligibility category, receipt of Supplemental Security Income (SSI), and date of birth for each enrollee. Those dually eligible for Medicare and Medicaid were excluded because Medicaid administrative claims do not capture complete service and pharmacy utilization records for this subpopulation. Schizophrenia diagnosed enrollees who ever received a substance use disorder (SUD) diagnosis (alcohol and drug psychoses ICD-9 codes 291 and 292, and other alcohol/drug abuse diagnoses with the exception of tobacco and antidepressant use -- 303, 304, 305.0, 305.2-305.7, and 305.9) were considered to have a SUD comorbidity.

For purposes of this study, a patient was considered to have schizophrenia if the enrollee had: (i) at least two inpatient and/or outpatient schizophrenia diagnoses (ICD-9 codes 295.0-295.9); ${ }^{21}$ or (ii) only one inpatient schizophrenia discharge diagnosis, but no diagnosis of any of the bipolar disorders; or (iii) only one outpatient schizophrenia diagnosis, but at least $50 \%$ of the enrollee's annual total mental health outpatient visits must have been represented by that single schizophrenia claim. Use of this $50 \%$ criterion increased the likelihood of capturing claims from the most difficult to engage patients with schizophrenia who presented for treatment on only a few occasions.

Using these sets of inclusion and exclusion criteria, our algorithms yielded 12,864 person-years of data covering the six fiscal years between 1994-1995 and 1999-2000, on average 2,144 per year. Demographic 
characteristics and other data for this study population are presented in Table 1. Mean age of the study population by year varies between 39.8 and $41.6,55-59 \%$ are in the Jacksonville county, $52-53 \%$ are female, more than $95 \%$ were covered by SSI, the proportion with substance use disorders varied from $10.6 \%$ to $12.9 \%$, blacks comprised about a third of the study population, whites accounted for slightly less than $50 \%$, and hispanics/all others constituted about $20 \%$ of the study population.

TABLE 1

SCHIZOPHRENIA STUDY POPULATION: JACKSONVILLE/ORLANDO, FLORIDA

\begin{tabular}{|c|c|c|c|c|c|c|}
\hline & \multicolumn{6}{|c|}{ FISCAL YEAR } \\
\hline & 1994-95 & $1995-96$ & 1996-97 & 1997-98 & 1998-99 & 1999-00 \\
\hline Person Years & 1998 & 2142 & 2248 & 2236 & 2082 & 2168 \\
\hline Age (years) & 40.5 & 40.2 & 39.8 & 40.5 & 41.2 & 41.6 \\
\hline Jacksonville \% & 56.8 & 55.4 & 56.0 & 57.4 & 59.4 & 57.5 \\
\hline Female \% & 53.4 & 52.8 & 51.7 & 52.0 & 51.8 & 53.1 \\
\hline Ever SSI \% & 95.7 & 95.5 & 95.7 & 96.2 & 97.6 & 97.6 \\
\hline Substance Use Disorder \% & 10.6 & 12.8 & 12.6 & 11.8 & 12.9 & 11.4 \\
\hline Black \% & 33.1 & 33.1 & 33.0 & 32.7 & 33.8 & 33.4 \\
\hline White \% & 48.8 & 47.8 & 48.1 & 47.6 & 47.4 & 45.8 \\
\hline Hispanic/All Other \% & 18.1 & 19.1 & 18.9 & 19.7 & 18.8 & 20.8 \\
\hline
\end{tabular}

\section{INFERRING TREATMENT QUALITY WITH ADMINISTRATIVE CLAIMS DATA}

We employed the PORT schizophrenia recommendations as a framework for classifying quality of care received by enrollees diagnosed with schizophrenia. More specifically, at the person-fiscal year level, we constructed a variety of PORT-based process measures, characterized as dichotomous indicator variables. Quality indicators include treatment types that are evidence-supported (e.g., various pharmacotherapypsychosocial treatment combinations), treatment types for which evidence is equivocal (e.g., vocational rehabilitation), and those not supported by evidence (e.g., only individual or group therapy without any antipsychotic pharmacotherapy).

For each person-year observation, the individual was classified as receiving as the only type of treatment: (i) any antipsychotic medication (“any AP Rx"); (ii) any atypical antipsychotic medication, 
including clozapine ("any AT, including clozapine"); (iii) any individual, group and/or family therapy ("any THY"); (iv) any psychosocial rehabilitation ("REHAB"); or as treatment dual combinations, (v) "any AP plus any THY"; (vi) "any AT plus any THY"; or as treatment triple combinations, (vii) "any AP plus any THY plus REHAB"; or (viii) "any AT plus any THY plus REHAB”. This classification scheme therefore consisted of four solo treatments, two dual combination treatments, two triple combination treatments, plus an "all other" miscellaneous treatment category. ${ }^{22}$ Note that a person-year observation could be in more than one treatment category, e.g., for a person prescribed an AT, he/she could be in (i) and (ii), and for a person prescribed an AT and participating in THY, in both (v) and (vi).

Use of these process indicator variables as measures of minimal quality of care admittedly generates a rather loose indicator of quality, e.g., whether a patient received any prescription for antipsychotics in a given fiscal year. Note that we do not assess whether the patient received adequate doses or adequate durations. Similarly, our psychological therapy quality measures are defined simply as whether the patient had at least one session in a given fiscal year, and we do not assess the "dose" or duration/frequency of psycotherapy utilization. While in general it is problematic to define criteria for appropriate levels of utilization, we believe it is reasonable to expect that a high proportion of patients with a persistent, chronic, disabling illness such as schizophrenia should receive at least one of these services (i.e., family therapy, group/individual therapy). In this sense, therefore, our quality measures reflect meeting only minimal standards of care. Nevertheless, as will be shown below, these classifications serve us very well in differentiating groups of people treated for schizophrenia.

\section{ECONOMETRIC FRAMEWORK}

We specify multivariate regression equations with the natural logarithm of annual mental healthrelated direct medical costs as the dependent variable. Regressors include patient-specific demographic measures (age, gender, race, county), enrollment history (months at risk, ever SSI), medical history (ever substance use disorder), and indicator variables for eight of the nine solo and combination treatment bundles 
(the omitted case is the all other, miscellaneous category). Estimation is by ordinary least squares, with standard errors adjusted for autocorrelation and clustering.

Because the decade of the 1990s was one of considerable changes in the treatment of persons with schizophrenia, we test for parameter stability over time using variants of the Chow test. In particular, in the unrestricted specifications all parameters are allowed to differ across the six fiscal years. In the stability constrained regression, fiscal year indicator variables were permitted to vary across years, but all other parameter estimates were constrained to be equal across fiscal years.

To obtain measures of predicted cost from the log-transformed dependent variable, it is necessary to retransform back from logarithmic to "natural" units. We employ the non-parametric smearing method of Duan [1983], and allow for heteroskedasticity (i.e., a different smearing factor) across fiscal years, but homoskedasticity within fiscal years.

\section{VII. $\quad$ RESULTS: QUALITY OF CARE, AND MENTAL HEALTH COSTS BY TREATMENT TYPE}

Table 2 presents use of various treatment types, by fiscal year. Recall that these quality measures reflect whether there was any utilization of a particular treatment type, and that no account is taken of whether the treatment was of adequate dose or duration (while doing so would augment our precision in defining quality, it would clearly be endogenous and thereby introduce econometric complications). Also, note that since the various treatment types can be used alone or in combination with others, within any given fiscal year the percentages will add up to more than $100 \%$.

TABLE 2

TREATMENT QUALITY MEASURES, IN PERCENTAGES

(May by used alone or in combination)

\begin{tabular}{|l|l|l|l|l|l|l|}
\hline & \multicolumn{7}{|c|}{ FISCAL YEAR } \\
TREATMENT & $\mathbf{1 9 9 4 - 9 5}$ & $\mathbf{1 9 9 5 - 9 6}$ & $\mathbf{1 9 9 6 - 9 7}$ & $\mathbf{1 9 9 7 - 9 8}$ & $\mathbf{1 9 9 8 - 9 9}$ & $\mathbf{1 9 9 9 - 0 0}$ \\
\hline Any Antipsychotic Prescription & $86.2 \%$ & $87.2 \%$ & $88.0 \%$ & $87.6 \%$ & $89.3 \%$ & $89.8 \%$ \\
\hline Any Atypical Rx (incl. Clozapine) & 19.2 & 22.9 & 34.4 & 44.9 & 53.2 & 61.2 \\
\hline Family Therapy & 0.6 & 0.7 & 0.8 & 0.8 & 0.5 & 0.6 \\
\hline Individual and/or Group Therapy & 52.4 & 53.0 & 47.4 & 31.2 & 34.8 & 30.4 \\
\hline Psychosocial Rehabilitation & 47.6 & 51.4 & 47.8 & 48.4 & 42.2 & 39.7 \\
\hline
\end{tabular}


Over the study period, use of antipsychotics was consistently very high, increasing slightly from $86 \%$ in 1994-1995 to 90\% in 1999-2000. More striking, however, is the dramatic three-fold increase in the use of the atypical antipsychotics (including clozapine), with the proportion of persons diagnosed with schizophrenia receiving atypical treatment increasing from $19 \%$ in $1994-95$ to $61 \%$ in $1999-2000$. By contrast, very few enrollees with schizophrenia received family therapy $(<1 \%$ in all years).

Although the PORT study recommended that individual and/or group psychotherapy accompany treatment with antipsychotic medications, the proportion of enrollees with schizophrenia receiving psychotherapy (alone or in combination therapy) decreased from slightly more than one-half (52-53\% in 199496) to $47 \%$ in $1996-97$, and then dropped sharply, reaching $30 \%$ in $1999-2000$. Notably, the reduction in use of this treatment type, for which PORT cited considerable clinical evidence concerning efficacy, was considerably larger than the reduction in use of psychosocial rehabilitation, which declined from 48\% in 1994 95 to $40 \%$ in 1999-2000. Psychosocial rehabilitation, a treatment type for which PORT noted the clinical evidence was equivocal, was utilized at a considerably higher rate than the $30 \%$ provision of individual and/or group therapy.

Mean mental health-related treatment spending, by type of individual treatment, is presented in Table 3, while that for specific combination treatments is given in Table 4. In terms of overall mental health spending for enrollees with schizophrenia, mean spending dropped from $\$ 7,655$ in 1994-95 to $\$ 7,000$ in 199798, and then increased in the last two fiscal years of the study period, ending up in 1999-2000 at $\$ 7,837$, about $2.4 \%$ higher than in 1994-95.

When stratified by individual treatment types, between 1994-95 and 1999-2000 yearly spending on treatment for users of any antipsychotic (AP, typical or atypical) increased about $1 \%(\$ 8,269$ to $\$ 8,365)$, while spending for users of any atypical antipsychotic (AT) decreased by almost 30\% $(\$ 13,889$ to $\$ 9,868)$, albeit to a slightly higher level in $1999-2000$ than for all antipsychotics $(\$ 9,868$ vs. $\$ 8,365)$. An even larger reduction in 
TABLE 3

\section{MEAN MENTAL HEALTH TREATMENT COSTS, BY TREATMENT TYPE WHEN USED AS SOLO TREATMENT}

(Cost per Person Year by Fiscal Year in Dollars)

\begin{tabular}{|c|c|c|c|c|c|c|}
\hline \multirow[b]{2}{*}{ TREATMENT } & \multicolumn{6}{|c|}{ FISCAL YEAR } \\
\hline & $1994-95$ & $1995-96$ & 1996-97 & $1997-98$ & 1998-99 & 1999-00 \\
\hline Overall Mean & $\$ 7,655$ & $\$ 7,192$ & $\$ 7,203$ & $\$ 7,000$ & $\$ 7,357$ & $\$ 7,837$ \\
\hline Any Antipsychotic Prescription & 8,269 & 7,647 & 7,703 & 7,532 & 7,798 & 8,365 \\
\hline Any Atypical Rx (incl. Clozapine) & 13,889 & 11,906 & 11,007 & 9,658 & 9,668 & 9,868 \\
\hline Individual and/or Group Therapy & 14,768 & 9,128 & 10,830 & 6,376 & 7,342 & 3,855 \\
\hline Psychosocial Rehabilitation & 7,448 & 7,201 & 6,772 & 8,190 & 6,370 & 7,022 \\
\hline
\end{tabular}

treatment costs was associated with users of individual and/or group therapy (THY), which fell almost $75 \%$ from $\$ 14,768$ in $1994-95$ to $\$ 3,855$ in $1999-2000$. Yearly mental health treatment costs for those receiving only psychosocial rehabilitation (REHAB) treatment declined about $6 \%$ from $\$ 7,448$ to $\$ 7,022$.

In the second and third panels of Table 4, yearly treatment costs are given for two dual combination treatments -- any AP with any THY, and any AT with any THY. By 1999-2000, the level of spending for those with any AP plus any THY dual combination therapy was about $23 \%$ higher than for those, with individuals any AP alone (\$10,282 vs. \$8,365) and about 2.67 times larger than with only THY (\$10,282 vs. $\$ 3,855)$. While the level of spending on care for the any AT plus any THY dual treatment in 1999-2000 was about $11 \%$ greater than that for any AP plus any THY $(\$ 11,393$ vs. $\$ 10,282)$, this dual combination treatment was about $15 \%$ higher than solo treatment with AT (\$11,393 vs. \$9,868), and almost three times larger than solo treatment with THY $(\$ 11,393$ vs. $\$ 3,855)$.

In terms of changes rather than levels, although yearly spending on care for people with any AP plus any THY combination treatment declined 3-4\% between 1994-95 and 1999-2000 (from $\$ 10,643$ to $\$ 10,282$ ), with the any AT plus any THY combination the decrease was a striking $28 \%$ (from $\$ 15,840$ to $\$ 11,393$ ).

The bottom two panels of Table 4 provide data on yearly spending on treatment data for two triple combination treatments. By 1999-2000, people with either of the two triple treatment combinations have spending levels that are about $20-25 \%$ higher than people with dual treatment combinations excluding 
TABLE 4

\section{MEAN MENTAL HEALTH TREATMENT COSTS, BY TREATMENT TYPE FOR COMBINATION THERAPIES}

(Cost per Person Year by Fiscal Year in Dollars)

\begin{tabular}{|c|c|c|c|c|c|c|}
\hline \multirow[b]{2}{*}{ TREATMENT } & \multicolumn{6}{|c|}{ FISCAL YEAR } \\
\hline & 1994-95 & $1995-96$ & 1996-97 & $1997-98$ & 1998-99 & 1999-00 \\
\hline Overall Mean & $\$ 7,655$ & $\$ 7,192$ & $\$ 7,203$ & $\$ 7,000$ & $\$ 7,357$ & $\$ 7,837$ \\
\hline Any AP Rx + Any THY & 10,643 & 9,899 & 9,520 & 10,444 & 9,557 & 10,282 \\
\hline AT Rx + Any THY & 15,840 & 13,983 & 12,746 & 12,442 & 11,062 & 11,393 \\
\hline Any AP Rx + Any THY + REHAB & 14,192 & 12,212 & 12,038 & 12,633 & 11,682 & 12,707 \\
\hline Any AT RX + Any THY + REHAB & 18,650 & 15,931 & 14,861 & 14,332 & 12,865 & 13,640 \\
\hline
\end{tabular}

Legend:

$\mathrm{Rx}=$ Prescription Drug

$\mathrm{AP}=$ Antipsychotic

$\mathrm{AT}=$ Atypical (including Clozapine) $\quad \mathrm{THY}=$ Individual, group or family therapy

$\mathrm{REHAB}=$ psychosocial rehabilitation

REHAB. Although yearly mental health-related costs with the any AP plus any THY plus REHAB treatment combination fell about 10\% between $1994-95$ and $1999-2000$ (from $\$ 14,192$ to $\$ 12,707$ ), the decline in costs with the any AT plus any THY plus REHAB triple combination treatment was even larger at 27\% (from $\$ 18,650$ to $\$ 13,640)$.

In summary, the Florida data on changes over time in treatment types suggest a mixed picture in terms of quality changes, with increased use of any atypical antipsychotic, and decreased use of individual and/or group therapy, as well as decreased use of psychosocial rehabilitation. These results on spending for care by type of treatment are suggestive, but they do not enable us to control for changing patterns of care and demographics, and do not allow us to assess what has happened to annualized spending for treating persons with schizophrenia, holding quality of care constant. Thus, we now turn to results from our multivariate regression analyses.

\section{RESULTS: ECONOMETRIC FINDINGS, AND IMPLICIT PRICE INDEXES}

Using the person-year as the unit of observation $(n=12,864)$, we estimate parameters in yearly multivariate regressions with log mental health care costs as the dependent variable, and include as regressors demographic variables, a substance use disorder indicator variable, and indicator variables for various solo, 
double and triple combination treatment types. We then pool across fiscal years as permitted by results of hypothesis tests for parameter stability over the six-year 1994-95 through 1999-2000 time period.

Results from tests for parameter stability indicated decisive rejection of the null hypothesis of parameter equality across years for all coefficients other than the constant term $\left(\mathrm{F}_{85,12756}=1.43\right.$, $\mathrm{p}$-value 0.0059). Since parameter equality across years is rejected, pooling is not supported, and thus in Table 5 we present parameter estimates from the yearly regressions. Recall that the omitted reference case is a male, caucasian, never had SSI or a substance use disorder, from Orlando, with a miscellaneous "all other" treatment type. Four sources of intertemporal instability merit particular attention.

TABLE 5

PARAMETER ESTIMATES FROM LOGARITHMIC ANNUAL TREATMENT COST EQUATION (Ratio of Parameter Estimate to Robust Standard Error in Parentheses)

\begin{tabular}{|c|c|c|c|c|c|c|}
\hline \multirow[b]{2}{*}{ VARIABLE } & \multicolumn{6}{|c|}{ FISCAL YEAR } \\
\hline & 1994-95 & $1995-96$ & 1996-97 & $1997-98$ & 1998-99 & 1999-00 \\
\hline \multirow[t]{2}{*}{ Constant } & 4.765 & 4.865 & 4.693 & 4.170 & 5.168 & 4.852 \\
\hline & $(13.08)$ & $(16.80)$ & $(14.26)$ & $(15.26)$ & $(13.19)$ & $(15.26)$ \\
\hline \multirow[t]{2}{*}{ Age } & 0.004 & 0.005 & 0.006 & 0.008 & 0.005 & 0.005 \\
\hline & $(1.51)$ & $(2.10)$ & $(2.72)$ & $(3.86)$ & $(2.17)$ & $(2.43)$ \\
\hline \multirow[t]{2}{*}{ Months at Risk } & 0.112 & 0.111 & 0.129 & 0.148 & 0.109 & 0.165 \\
\hline & $(4.13)$ & $(5.07)$ & $(5.14)$ & $(6.68)$ & $(3.35)$ & $(6.74)$ \\
\hline \multirow[t]{2}{*}{ Ever SSI } & 0.202 & 0.248 & 0.256 & 0.464 & 0.076 & -0.077 \\
\hline & $(1.33)$ & $(1.92)$ & $(1.80)$ & $(4.07)$ & $(0.44)$ & $(0.59)$ \\
\hline \multirow[t]{2}{*}{ Female } & 0.184 & 0.099 & 0.114 & 0.136 & 0.186 & 0.120 \\
\hline & $(3.45)$ & $(1.95)$ & $(2.28)$ & $(2.87)$ & $(4.04)$ & $(2.76)$ \\
\hline \multirow[t]{2}{*}{ Black } & -0.169 & -0.157 & -0.234 & -0.221 & -0.266 & -0.298 \\
\hline & $(2.86)$ & $(2.74)$ & $(4.18)$ & $(4.14)$ & $(5.16)$ & $(6.09)$ \\
\hline \multirow[t]{2}{*}{ Hispanic } & 0.122 & -0.058 & -0.104 & -0.132 & 0.359 & -0.525 \\
\hline & $(0.34)$ & $(0.23)$ & $(0.38)$ & $(0.40)$ & $(1.29)$ & $(2.16)$ \\
\hline \multirow[t]{2}{*}{ All Other Races } & -0.140 & -0.124 & -0.124 & -0.230 & -0.204 & -0.269 \\
\hline & $(2.03)$ & $(1.87)$ & $(1.90)$ & $(3.64)$ & $(3.18)$ & $(4.66)$ \\
\hline \multirow[t]{2}{*}{ Jacksonville } & 0.099 & -0.065 & 0.239 & 0.224 & 0.182 & 0.143 \\
\hline & $(1.74)$ & $(1.24)$ & $(4.63)$ & $(4.67)$ & $(3.76)$ & $(3.20)$ \\
\hline \multirow[t]{2}{*}{ Ever Substance Use Disorder } & 0.168 & 0.052 & 0.205 & 0.162 & 0.109 & 0.051 \\
\hline & $(2.00)$ & $(0.66)$ & $(2.95)$ & $(2.29)$ & $(1.65)$ & $(0.70)$ \\
\hline \multirow[t]{2}{*}{ Only an AP } & 0.610 & 0.519 & 0.544 & 0.576 & 0.615 & 0.621 \\
\hline & $(4.49)$ & $(3.70)$ & $(4.35)$ & $(4.58)$ & $(4.32)$ & $(4.62)$ \\
\hline \multirow[t]{2}{*}{ Only any AT/Clozapine } & 0.824 & 0.766 & 0.798 & 0.785 & 0.860 & 0.870 \\
\hline & $(7.01)$ & $(8.95)$ & $(10.39)$ & $(13.92)$ & $(13.78)$ & $(15.51)$ \\
\hline \multirow[t]{2}{*}{ Only any THY } & 0.798 & 0.670 & 0.245 & 0.252 & 0.418 & 0.199 \\
\hline & $(4.61)$ & $(3.45)$ & $(1.48)$ & $(1.43)$ & $(2.22)$ & $(1.04)$ \\
\hline
\end{tabular}




\begin{tabular}{|l|l|l|l|l|l|l|}
\hline Rehabilitation Only & 1.318 & 1.213 & 0.975 & 0.854 & 0.910 & 0.874 \\
\hline & $(17.63)$ & $(16.31)$ & $(13.96)$ & $(14.86)$ & $(14.68)$ & $(15.87)$ \\
\hline Any AP + any THY & -0.264 & -0.092 & -0.138 & -0.116 & -0.240 & -0.293 \\
\hline & $(1.37)$ & $(0.43)$ & $(0.73)$ & $(0.55)$ & $(1.09)$ & $(1.26)$ \\
\hline Any AT + any THY & 0.155 & 0.152 & 0.217 & -0.015 & 0.063 & 0.238 \\
\hline & $(0.87)$ & $(0.97)$ & $(1.64)$ & $(0.10)$ & $(0.47)$ & $(1.58)$ \\
\hline Any AP + Any THY + REHAB & -0.038 & -0.024 & 0.142 & 0.266 & 0.290 & 0.565 \\
\hline & $(0.34)$ & $(0.21)$ & $(1.18)$ & $(1.79)$ & $(2.14)$ & $(3.48)$ \\
\hline Any AT + Any THY + REHAB & -0.382 & -0.416 & -0.392 & -0.234 & -0.628 & -0.786 \\
\hline & $(2.47)$ & $(2.76)$ & $(2.85)$ & $(1.30)$ & $(4.24)$ & $(4.53)$ \\
\hline R-Squared & 0.400 & 0.374 & 0.335 & 0.364 & 0.349 & 0.375 \\
\hline Root MSE & 1.131 & 1.130 & 1.136 & 1.080 & 1.033 & 0.984 \\
\hline Smearing Factor & 1.926 & 1.926 & 1.853 & 1.800 & 1.666 & 1.607 \\
\hline N & 1998 & 2139 & 2247 & 2234 & 2081 & 2166 \\
\hline
\end{tabular}

First, based on the yearly regressions, the evidence suggests that relative to caucasians, blacks are receiving increasingly less costly treatment, ceteris paribus; the cost differential is about $-16 \%$ in $1994-95$, and increases to about $-26 \%(\exp (-0.298)=0.742)$ by $1999-2000$. For hispanics, the trend is not as clear. Relative to caucasians, individuals from all other races are also receiving increasingly less costly treatment, increasing from $-13 \%$ in $1994-95$ to $-24 \%$ in $1999-2000$. Related findings on treatment differentials by race have been reported in the literature by others. ${ }^{23}$

Second, the spending premium for treating schizophrenia in individuals who have ever had a substance use disorder is positive, but appears to be falling over time. Although this premium was about $18 \%$ and 23\% in 1994-95 and 1996-97, respectively, ceteris paribus, by 1999-2000 it had fallen to about 5\%.

Third, while the yearly treatment spending premia for only AP and only AT increased slightly between 1994-95 and 1999-2000 (by 2\% and 6\%, respectively), for only THY the annualized treatment costs fell by $75 \%$, even as those for psychosocial rehabilitation fell $34 \%$.

Fourth, although there are no general significant trends for annualized treatment spending premia involving the two dual combination therapies (any AP plus any THY, and any AT plus any THY), the two triple combination therapies display quite different trends. In particular, while the annualized spending premia for any AP plus any THY plus REHAB changes from insignificantly negative in 1994-95 to significantly positive in 1999-2000, for the any AT plus any THY plus REHAB triple combination therapy the negative premium doubles from -0.382 in $1994-95$ to -0.786 in $1999-2000$. 
It is also worth noting that although the $\mathrm{R}^{2}$ varies from about 0.34 to 0.40 , there is a general downward trend in the root mean squared error across the fiscal years, falling about $15 \%$ from 1.131 in $1994-$ 95 to 0.984 in 1999-2000. Duan's smearing factor, which reflects the mean value of the exponentiated residuals from the yearly log-cost regressions, also declines over time, by $16.6 \%$ from 1.926 in $1994-95$ to 1.607 in $1999-2000$, an AAGR of $-3.56 \%$ per year..

Since the data do not support pooling across fiscal years, it is not possible to use exponentiated yearly indicator variable coefficient estimates to obtain quality-constant price index measures of treatment cost over time. ${ }^{24}$ Instead, we hold quality and other characteristic variables fixed over time, and then compare predicted spending. But at what years' values does one hold quality fixed? Should one employ base year quality and other characteristics fixed over time, those from the final year, or those from intervening years? We follow price index methodology, and for any bilateral time comparison, and take the geometric mean of price indexes based on the first and final years' values of the quality and characteristics variables. ${ }^{25}$

More specifically, we first take the composition of treatment types, demographic characteristics and substance use disorder data from the 1994-95 base year cohort. Holding these variables fixed over time for each individual, we then predict log annual mental health costs for each individual for each subsequent year, using the yearly parameter estimates. Since we hold the treatment type and other variables fixed over time at their base year levels, this is analogous to a fixed weight Laspeyres price index procedure, where our procedure is now interpreted as holding quality fixed at the 1994-95 base year levels. We then retransform from predicted log spending to natural cost units, take the mean of this predicted log spending, and then multiply by Duan's [1983] smearing factor estimate, separately for each year, to obtain predicted total mental health spending. This yearly predicted total mental health spending is then normalized by the 1994-95 base year predicted spending to convert the predicted spending series into a price index, with $1994-95=100$.

We then do the polar extreme of this, using instead the composition of treatment types, demographic characteristics and substance use disorder values from the final 1999-2000 fiscal year in our study sample. We follow similar procedures in using the yearly parameter estimates to predict log- spending and retransform to natural spending units, then employ the yearly Duan smearing factor estimate, and finally, normalize to 1994- 
95. Use of this procedure is analogous to using the current time period fixed weights in the Paasche price index formulae, and is interpreted here as holding treatment quality constant at the 1999-2000 levels.

As has been emphasized by others, since in the consumer demand context the Laspeyres and Paasche price indexes bracket true changes in the cost-of-living, researchers have long advocated using the Fisher Ideal price index (the geometric mean of the Paasche and Laspeyres) as an even-handed compromise in choice of weights in making bilateral time series comparisons. ${ }^{26}$ We call these three price indexes the fixed weight Laspeyres, the fixed weight Paasche, and the fixed weight Fisher price index.

When the composition of treatment bundles changes considerably over time, as has occurred in the context of schizophrenia during our 1994-1995 through 1999-2000 time period, growth rates of qualityconstant price indexes can vary considerably, depending on which years' weights are employed, i.e., those of 1994-1995, or of 1999-2000. To reduce this sensitivity to choice of fixed weights, price index researchers typically employ chained price indexes, in which weights are sequentially updated with each pair of adjacent time periods. Unlike the case with the fixed weight Laspeyres, fixed weight Paasche and fixed weight Fisher price indexes, with a chained Laspeyres index between fiscal years, say, 1996-1997 and 1997-1998, the bilateral time comparison would employ updated 1996-1997 base year weights, while the chained Paasche index would employ updated 1997-1998 current year weights. The chained Fisher Ideal price index is then computed as the geometric mean of the chained Laspeyres and chained Paasche price indexes. We compute both fixed weight and chained price indexes. Results are presented in Table 6.

TABLE 6

QUALITY-CONSTANT FIXED WEIGHT AND CHAINED PRICE INDEXES

(Based on Yearly Retransformed Logarithmic Regressions)

\begin{tabular}{|l|cc|cc|cr|}
\hline \multirow{2}{*}{ FISCAL YEAR } & \multicolumn{2}{|c|}{ LASPEYRES } & \multicolumn{2}{c|}{ PAASCHE } & \multicolumn{2}{c|}{ FISHER IDEAL } \\
\hline & FIXED & CHAIN & FIXED & CHAIN & FIXED & CHAIN \\
\hline $\mathbf{1 9 9 4 - 1 9 9 5}$ & 100.00 & 100.00 & 100.00 & 100.00 & 100.00 & 100.00 \\
\hline $\mathbf{1 9 9 5 - 1 9 9 6}$ & 85.98 & 85.98 & 83.75 & 85.63 & 84.86 & 85.80 \\
\hline $\mathbf{1 9 9 6 - 1 9 9 7}$ & 76.51 & 77.30 & 85.66 & 79.62 & 80.96 & 78.45 \\
\hline $\mathbf{1 9 9 7 - 1 9 9 8}$ & 73.54 & 71.75 & 78.45 & 73.22 & 75.95 & 72.48 \\
\hline $\mathbf{1 9 9 8 - 1 9 9 9}$ & 73.78 & 71.49 & 78.33 & 72.51 & 75.98 & 72.00 \\
\hline $\mathbf{1 9 9 9 - 2 0 0 0}$ & 75.25 & 74.67 & 81.85 & 75.77 & 78.48 & 75.22 \\
\hline AAGR & $-5.53 \%$ & $-5.68 \%$ & $-3.93 \%$ & $-5.40 \%$ & $-4.73 \%$ & $-5.54 \%$ \\
\hline
\end{tabular}


With the fixed weight Laspeyres index (first column), where treatment quality is held constant over all years at the 1994-95 values, the quality-constant price index drops about 14\% in 1995-96, it drops another almost ten percentage points in 1996-97, fall slightly, then increases in 1999-2000, ending up at 75.25 in 1999-2000, a cumulative price decline of $24.75 \%$, and an average annual growth rate (AAGR) of $-5.53 \%$.

For the fixed weight Paasche index (third column), where treatment quality is held constant over all years at the 1999-2000 values, the quality-constant price index drops even more to about 84 in 1995-96, but unlike the fixed weight Laspeyres that falls, the fixed weight Paasche increases to almost 86 in 1996-97. The fixed weight Paasche then falls to about 78 in 1997-98 and 1998-99, and then increases slightly, ending up at 81.85 in $1999-2000$, a cumulative price decline of $18.15 \%$, and an AAGR of $-3.93 \%$. Notice that the fixed weight Laspeyres declines considerably more rapidly than the fixed weight Paasche, $-5.53 \%$ vs. $-3.93 \%$.

With the fixed weight Fisher Ideal price index (column 5, calculated as the square root of the product of the column 3 fixed weight Paasche and the column 1 Laspeyres indexes), there is a 15\% decline in 1995-96, followed by four percentage point declines in 1996-97 and 1997-98, no change in 1998-1999, and an increase in 1999-2000. The fixed weight Fisher is always in between the fixed weight Laspeyres and Paasche indexes, ending up at 78.48 in $1999-2000$, a $21.52 \%$ cumulative decline reflecting an AAGR of $-4.73 \%$.

With the chained price indexes, differences between the Laspeyres and Paasche price indexes become considerably smaller than with the fixed weight variants. As is seen in columns 2,4 and 6 of Table 6 , the AAGR for the chained Laspeyres at $-5.68 \%$ is only very slightly different from that of the chained Paasche at $-5.40 \%$, with the Fisher being in between at $-5.54 \%$.

Aficionados of price index measurement will appreciate that a somewhat surprising result here is that the fixed weight and chained Laspeyres price index fall more rapidly than do their corresponding Paasche price indexes, counter to the usual inequality between these two indexes. A related empirical finding, where the Paasche price index increased more rapidly than the Laspeyres, has been reported by Berndt, Busch and Frank [2001] in the context of treatment costs for individuals diagnosed with acute phase major depression. ${ }^{27}$ 
The conventional wisdom result that Laspeyres indexes will increase by more (decrease by less) than the Paasche price indexes is based on the assumption of a constant utility framework with stationary and homothetic preferences, for in that context price relatives are negatively correlated with quantity relatives. As has been shown by, among others, Allen [1925], in certain contexts (such as when viewed from the point of view of a multiproduct competitive supplier), price and quantity relatives can be positively correlated, resulting in the reversal of the usual Paasche increasing less than the Laspeyres inequality. Since observed price and quantity movements reflect the net outcome of changes in demand and supply, differing inequalities between measured Paasche and Laspeyres price index changes can occur over time, reflecting a variety of underlying shifts in demand and supply. In the current context, one can interpret the reversal of the usual Paasche Laspeyres inequality as reflecting physicians' learning about the efficacy and increased tolerability of the more costly atypicals antipsychotics, changing their prescribing behavior towards the more costly atypicals, shifting "demand" curves to the right, thereby generating positive correlations between price and quantity relatives for the atypicals. ${ }^{28}$

In summary, although changes in mean mental health-related treatment costs for individuals diagnosed with schizophrenia, unadjusted for changes in treatment quality over time, have increased about $2.4 \%$ between 1994-95 and 1999-2000 (an AAGR of 0.5\%), holding treatment quality constant over time results in a cumulative price decline of about $22 \%$ with the fixed weight Fisher Ideal index, an AAGR of $-4.73 \%$. Holding treatment quality constant in sequentially updated chained Fisher Ideal indexes yields a slightly larger cumulative decline of almost $25 \%$, and an AAGR of $-5.54 \%$.

\section{IX. $\quad$ LIMITATIONS AND CONCLUDING REMARKS}

The data that form the empirical foundation for this study come from two counties in Florida, covering the 1994-2000 time period. Medicaid mental health services in these two counties are managed only very slightly, and in particular, these data do not capture effects of carve-outs to managed behavioral health care organizations. 
Our measures of quality of care are quite coarse and lenient in that we only require that within a given fiscal year, the enrollee diagnosed with schizophrenia received, for example, any antipsychotic prescription, or any individual or group psychotherapy. We have not imposed requirements that the treatments received involved appropriate doses over adequate durations of time. Nevertheless, outside of antipsychotic medications most people do not receive evidence-based elements of care. Within each of the nine distinct treatment types we identify, we have not examined whether the intensity of treatment has changed over time, e.g., whether the number of prescriptions of any antipsychotic, or the number of sessions with individual or group psychotherapy, have changed over time.

Our empirical analysis is based on retrospective administrative claims data from Medicaid, and limitations from these types of databases are well-known. Of particular importance is the fact that we cannot observe measures of patient illness severity, nor can we observe the various facets of patient outcomes from treatment. While Medicaid claims for schizophrenia have been demonstrated to be an accurate way to develop a schizophrenia cohort data set, there is also evidence that people who meet criteria for schizophrenia by clinical examination may not be diagnosed as such in the claims data. Thus, while we have likely maximized the "true positives", we are less confident of the "false negatives" that did not meet these cohort criteria and therefore are not included in the study.

With these limitations in mind, we conclude that there have been substantial changes in the composition of treatment types between 1994 and 2000 for individuals diagnosed with schizophrenia in two Florida counties. Almost $90 \%$ are receiving treatment with antipsychotic medications, and the proportion receiving an atypical antipsychotic tripled from about 19\% to $61 \%$ over the $1994-95$ to $1999-2000$ time period. These treatments are generally consistent with PORT recommendations. On the other hand, the proportion receiving any individual and/or group therapy declined from about 50\% to 30\% between 1994 and 2000; PORT recommends that medication and psychological treatments be combined for individuals diagnosed with schizophrenia. Finally, the proportion of individuals receiving psychosocial rehabilitation treatment, a treatment for which the PORT study indicated that supporting clinical evidence for efficacy was equivocal, declined from about 50\% to $40 \%$ between 1994 and 2000. In sum, the implications of this data for quality 
improvement in the treatment of individuals with schizophrenia are mixed. What is clear is that a substantial portion of treatment is not supported by clinical evidence.

Unadjusted for changes in treatment quality over time, the mean per person-year mental health care costs for treating schizophrenia have increased about $2.4 \%$ between $1994-95$ and $1999-2000$, or about $0.5 \%$ per year. Although there is some variability among them depending on choice of weights, quality-constant Fisher ideal price indexes have declined by 22-25\% between 1994-1995 and 1999-2000, implying AAGRs of $-4.73 \%$ (fixed weight) to $-5.54 \%$ (chained).

An important implication of these findings is that, when combined with these price declines, the observed substantial increases over time in expenditures on mental health care treatment for persons with schizophrenia therefore reflect primarily increases in the number of individuals being treated, and not an increase in the annualized costs of treating individuals diagnosed with schizophrenia. However, much of the care given these individuals is not supported by evidence-based medicine. 


\section{REFERENCES}

Abel, Jaison R., Ernst R. Berndt and Alan G. White [2003], "Price Indexes for Microsoft's Personal Computer Software Products, 1993-2001," Boston, MA: Analysis Group, Inc., unpublished manuscript, June.

Alegria, Margarita, Debra Joy Perez and Sandra Williams [2003], "The Role of Public Policies in Reducing Mental Health Status Disparities for People of Color”, Health Affairs, 22(5):pp. 51-64.

Allen, R. G. D. [1975], Index Numbers in Theory and Practice, Chicago: Aldine Publishing Company.

American Psychiatric Association [1994], Diagnostic and Statistical Manual of Mental Disorders, Fourth Edition, Washington DC.

Berndt, Ernst R. [2002], "Trends and Drivers of Expenditures on Psychotropic Drugs in the U.S.," Presentation at the National Institute of Mental Health Pharmacoeconomics Research Workshop, Bethesda MD, May 23.

Berndt, Ernst R., Ashoke Bhattacharjya, David N. Mishol, Almudena Arcelus and Thomas Lasky [2002], "An Analysis of the Diffusion of New Antidepressants: Variety, Quality, and Marketing Efforts," Journal of Mental Health Policy and Economics, 5:pp. 3-19.

Berndt, Ernst R., Anupa Bir, Susan H. Busch, Richard G. Frank and Sharon-Lise T. Normand [2002], "The Medical Treatment of Depression, 1991-1996: Productive Inefficiency, Expected Outcome Variations and Price Indexes," Journal of Health Economics, 21(3):pp. 373-396.

Berndt, Ernst R., Susan H. Busch and Richard G. Frank [2001], "Treatment Price Indexes for Acute Phase Major Depression," ch. 12 in David M. Cutler and Ernst R. Berndt, eds., Medical Care Output and Productivity, Studies in Income and Wealth, Vol. 61, Chicago: University of Chicago Press for the National Bureau of Economic Research, pp. 463-505.

Berndt, Ernst R., Iain M. Cockburn and Zvi Griliches [1996], "Pharmaceutical Innovations and Market Dynamics: Tracking Effects on Price Indexes of Antidepressant Drugs," Brookings Papers on Economic Activity: Microeconomics, pp. 133-188.

Berndt, Ernst R., David M. Cutler, Richard G. Frank, Joseph E. Newhouse and Jack E. Triplett [2000], "Medical Care Prices and Output," in Anthony Culyer and Joseph E. Newhouse, eds., Handbook of Health Economics, Amsterdam: Elsevier, pp. 119-180.

Berndt, Ernst R., Robert S. Pindyck and Pierre Azoulay [2003], "Consumption Externalities and Diffusion in Pharmaceutical Markets: Antiulcer Drugs," Journal of Industrial Economics, 51(2):pp. 243-270.

Berndt, Ernst R. and Neal J. Rappaport [2001], "Price and Quality of Desktop and Mobile Personal Computers: A Quarter Century Historical Overview," American Economic Review, 91(2),May:pp. 168-273.

Blazer, D. G., C. F. Hyobels, E. M. Simonsick and J. T. Hanlon [2000], "Marked Differences in Antidepressant Use by Race in an Elderly Community Sample: 1986-1996," American Journal of Psychiatry, 157:pp. 1089-1094.

Busch, Alisa B., Richard G. Frank and Anthony F. Lehman [2003], "The Effect of a Managed Behavioral Health Care Carve-Out on Quality of Care for Medicaid Patients Diagnosed with Schizophrenia," Archives of General Psychiatry (in press). 
Busch, Alisa B., Davina Y. C. Ling and Shelly F. Greenfield [2003], "Guideline Publication and Changes in BPAD-I Disorder Treatment," poster presented at the 2003 Annual Meetings of the American Psychiatric Association, May.

Busch, Susan H. [2002], "Specialty Health Care, Treatment Patterns and Quality: The Impact of a Mental Health Carve-Out on Care for Depression," Health Services Research, 37(6):pp. 1583-1601.

Croghan, Thomas W., Catherine A. Melfi, William E. Crown and Anita Chawla [1998], "Cost-Effectiveness of Antidepressant Medications," Journal of Mental Health Policy and Economics, 1:pp. 109-117.

Cutler, David M., Mark McClellan, Joseph E. Newhouse and Dahlia Remler [1998], "Are Medical Prices Declining? Evidence from Heart Attack Treatments," Quarterly Journal of Economics, 113(4):pp. 991-1024.

Diewert, W. Erwin [1993], "The Economic Theory of Index Numbers: A Survey," ch. 7 in W. Erwin Diewert and Alice O. Nakamura, eds., Essays in Index Number Theory, Vol. 1, London: North-Holland, pp. 177-221.

Diewert, W. Erwin [1992], "Fisher Ideal Output, Input and Productivity Indexes Revisited," Journal of Productivity Analysis, 3:pp. 211-248.

Duan, Naihua [1983], "Smearing Estimate: A Nonparametric Retransformation Method," Journal of the American Statistical Association, 78:pp. 605-610.

Duggan, Mark G. [2003], "Does Medicaid Pay Too Much for Prescription Drugs? A Case Study of Atypcial Anti-Psychotics," Cambridge, MA: National Bureau of Economic Research, Working Paper No. 9626, April.

F-D-C Reports [2003], "FDA Sides With Lilly: Seeks Class Warning on Antipsychotic Diabetes Risk”, The Pink Sheet, 65(38), September 22, pp. 26-28.

Frank, Richard G. and Rena Conti [2003], "Mental Health Policy and Psychotropic Drugs," Issue paper prepared for the Sub-Committee on Psychiatric Medications of the President's Mental Health Commission, 24 January.

Frank, Richard G., Ernst R. Berndt and Susan M. Busch [1999], "Price Indexes for the Treatment of Depression," in Jack E. Triplett, ed., Measuring the Prices of Medical Treatments, Washington DC: The Brookings Institution, pp. 72-102.

Frank, Richard G., Susan M. Busch and Ernst R. Berndt [1998], "Measuring Prices and Quantities of Treatments for Depression," American Economic Review, 88(2):pp. 106-111.

Frank, Richard G., Thomas G. McGuire and Joseph E. Newhouse [1995], "Risk Contracts in Managed Mental Health Care," Health Affairs 14(3):pp. 50-64.

Frank, Richard G., Thomas G. McGuire, Sharon-Lise T. Normand and Howard Goldman [1999], "The Value of Mental Health Care at the System Level," Health Affairs, 18(5):pp. 71-88.

Geiger-Brown, J. et al. [2002], "The Concordance of Medicaid Claims, Survey and Research Diagnoses for Patients with Serious and Persistent Mental Illness", University of Maryland, Department of Psychiatry.

Hafner, H., K. Maurer, W. Loffler, B. Fatkenheuer, W. van der Heiden, A. Riecher-Rossler, S. Behrens, and W.F. Gattaz [1994], "The Epidemiology of Early Schizophrenia: Influence of Age and Gender on Onset and Early Course," British Journal of Psychiatry, Supplement, April, 23:pp. 29-38. 
Lave, Judith R., Richard G. Frank, H.C. Schulberg and M. S. Kamlet [1998], "Cost-effectiveness of Treatments for Depression in Primary Care Practice," Archives of General Psychiatry, 55:pp. 645-651.

Lehman, Anthony F. [1999], "Quality of Care in Mental Health: The Case of Schizophrenia," Health Affairs, 18(5):pp. 52-65.

Lehman, Anthony F. et al. [1998a], "Translating Research into Practice: The Schizophrenia Patient Outcomes Research Team (PORT) Treatment Recommendations," Schizophrenia Bulletin, 24(1):pp. 1-10.

Lehman, Anthony F. et al. [1998b], "Patterns of Usual Care for Schizophrenia: Initial Results from the Schizophrenia Patient Outcomes Research Team (PORT) Client Survey," Schizophrenia Bulletin, 24(1):pp.1119.

Ling, Davina Y. C., Ernst R. Berndt and Richard G. Frank [2003], "General Purpose Technologies, Technology-Skill Complementarity, and the Diffusion of New Psychotropic Drugs Among Medicaid Populations," Boston, MA: Harvard Medical School, unpublished manuscript, June.

Ling, Davina Y. C., Richard G. Frank and Ernst R. Berndt [2003], "Behavioral Health Carve-Outs and Psychotropic Drug Spending in Medicaid Populations," Boston, MA: Harvard Medical School, Division of Health Care Policy, unpublished manuscript, March.

Ling, Davina Y. C., Alisa B. Busch, Richard G. Frank and Juliana Pakes [2002], "Treatment Price Indexes for Bipolar Disorder," poster presentation at NIMH Economics of Mental Health Workshop, Bethesda MD, 24 September.

Lurie, N., et al. [1992], "Accuracy of Diagnoses of Schizophrenia in Medicaid Claims," Hospital and Community Psychiatry, 43(1):pp.69-71.

Melfi, Catherine A., Thomas W. Croghan, M. Hanna and R. Robinson [2000], "Racial Variation in Antidepressant Treatment in a Medicaid Population," Journal of Clinical Psychiatry, 61:pp. 16-21.

Merck Medical Manual of Medical Information [1997], Home Edition, Whitehouse Station, N.J.: Merck Research Laboratories.

National Academy of Sciences [2002], At What Price? Conceptualizing and Measuring the Cost-of-Living and Price Indexes, Panel on Conceptual, Measurement and Other Statistical Issues in Developing Cost-ofLiving Indexes, Charles Schultze and Christopher Mackie, eds., Committee on National Statistics, National Research Council, 332 pp.

Normand, Sharon-Lise T., Richard G. Frank and Thomas G. McGuire [2002], "Using Elicitation Techniques to Estimate the Value of Ambulatory Treatments for Major Depression," Medical Decision Making, May/June, pp. 245-261.

Rosenheck, Robert A., J. Cramer, E. Allan et al. [1999], "Cost-effectiveness of Clozapine in Patients with High and Low Level Hospital Use," Archives of General Psychiatry, 56:pp. 565-572.

Rosenheck, Robert A., J. Cramer, W. Xu, J. Thomas, W. Henderson, L. K. Frisman, C. Fye and D. Charney [1997], "A Comparison of Clozapine and Haloperidol in the Treatment of Hospitalized Patients with Refractory Schizophrenia, New England Journal of Medicine, 337:pp. 809-815.

Rupp, Agnes and S. Keith [1993], "The Costs of Schizophrenia: Assessing the Burden," Psychiatric Clinics of North America, 16o(2):pp. 413-423. 
Schwalberg, R. et al. [2002], "Medicaid Outpatient Prescription Drug Benefits: Findings from a National Survey and Selected Case Study Highlights," Kaiser Family Foundation, available at $<$ www.kff.org $>$, accessed December 18.

Shapiro, Irving L., Matthew Shapiro and David Wilcox [2001], "A Price Index for Cataract Surgery," in David M. Cutler and Ernst R. Berndt, eds., Medical Output and Productivity, Chicago: University of Chicago Press for the National Bureau of Economic Research, pp. 411-438.

Shern, D. L. et al. [2001], "Evaluation of Florida's Prepaid Mental Health Plan: Year 4 Report, 2001," Tampa, Louis de la Parte Florida Mental Health Institute, University of South Florida.

Shern, D. L. et al. [2000], "Evaluation of Florida's Prepaid Mental Health Plan Year 3 Report, 2000," Tampa: University of South Florida.

Snowden, L. R. and K. Thomas [2000], "Medicaid and African American Outpatient Mental Health Treatment," Mental Health Services Research, 2(2):pp. 115-120.

Triplett, Jack E. [2001], "What's Different about Health? Human Repair and Car Repair in the National Accounts," in David M. Cutler and Ernst R. Berndt, eds., Medical Output and Productivity, Chicago:

University of Chicago Press for the National Bureau of Economic Research, pp. 15-94.

Triplett, Jack E. [1999], "Accounting for Health Care: Integrating Price Index and Cost-Effectiveness Research," in Jack E. Triplett, ed., Measuring the Prices of Medical Treatments, Washington DC: The Brookings Institution, pp. 220-250.

Triplett, Jack E. [1992], "Economic Theory of BEA's Alternative Quantity and Price Indexes," Survey of Current Business, 72:pp. 49-52.

United States Department of Health and Human Services [1999], Mental Health: A Report of the Surgeon General, Rockville MD: (need to fill in).

Wells, Kenneth, Roland M. Sturm, C. Sherbourne and L. Meredith [1996], Caring for Depression: A RAND Study, Cambridge, MA: Harvard University Press. 


\section{FOOTNOTES}

${ }^{1}$ For overviews, see Berndt [2002], Busch [2002], Duggan [2003], Frank and Conti [2003], Ling, Berndt and Frank [2003], Ling, Frank and Berndt [2003], and Wells et al. [1996].

${ }^{2}$ See for example Buck, Miller and Bae (2000) in the context of the Medicaid program.

${ }^{3}$ See Lehman et al (1998a).

${ }^{4}$ A preliminary study of price indexes for the treatment of bipolar disorders is that by Ling, Busch, Frank and Pakes [2002].

${ }^{5}$ Frank and Conti [2003].

${ }^{6}$ See, for example, Duggan [2003].

${ }^{7}$ The information provided here is largely taken from The Merck Manual of Medical Information [1997], pp. 435439.

${ }^{8}$ Hafner et al. [1994].

${ }^{9}$ Rupp and Keith [1993], and Lehman [1999].

${ }^{10}$ For further discussion, see American Psychiatric Association, Diagnostic and Statistical Manual of Mental Disorders [1994], pp. 273-315.

${ }^{11}$ Lehman et al. [1998a,b] and Lehman [1999].

${ }^{12}$ See, for example, F-D-C reports [2003].

${ }^{13}$ Lehman [1999], p. 53.

${ }^{14}$ Lehman [1999], p. 56.

${ }^{15}$ Lehman [1999], p. 56.

${ }^{16}$ Lehman [1999], pp. 56-57.

${ }^{17}$ Lehman [1999], p. 57.

${ }^{18}$ Lehman [1999], p. 58.

${ }^{19}$ Lehman [1999], p. 64.

${ }^{20}$ For other discussions of the Florida Medicaid data, see Shern et al. [2001, 2002], and Busch, Frank and Lehman [2003].

${ }^{21}$ The validity of the Medicaid administrative claims data in identifying persons with schizophrenia has been discussed by Lurie et al. [1992]. For further discussion, see Busch, Frank and Lehman [2003]. 
${ }^{22}$ The PORT study recommends assertive community treatment, which includes but is not limited to case management. Within the Medicaid administrative claims data, there is no specific procedure code for assertive community treatment, and the case management codes that do exist could reflect a heterogeneous set of services, many of which could be unrelated to the PORT recommendations. Therefore we exclude case management as a quality measure in this analysis.

${ }^{23}$ See, for example, Alegria et al. [2003], Blaer et al. [2000], Croghan et al. [1998], Lehman [1999], Melfi et al. [2000], and Snowden and Thomas [2000].

${ }^{24}$ For further discussion, see Berndt, Bir, Busch, Frank and Normand [2002], Berndt, Cockburn and Griliches [1996], and National Academy of Sciences [2002].

${ }^{25}$ For further discussion, see Allen [1975] and Berndt-Rappaport [2001].

${ }^{26}$ See Berndt and Rappaport [2001]. For further discussion, see Allen [1975], Diewert [1992, 1993], and Triplett [1992].

${ }^{27}$ Berndt, Busch and Frank [2001], Table 12.7, p. 491.

${ }^{28}$ For further discussion and references, see Abel, Berndt and White [2003]. 